\title{
Relação lisina digestível:proteína bruta em dietas para frangos de corte no período de 1 a 21 dias de idade. Desempenho e metabolismo ${ }^{1}$
}

\section{Kênia Ferreira Rodrigues ${ }^{2}$, Paulo Borges Rodrigues ${ }^{3}$, Rilke Tadeu Fonseca de Freitas ${ }^{3}$, Antonio Gilberto Bertechini ${ }^{3}$, Luiz Fernando Teixeira Albino ${ }^{4}$, Édison José Fassani ${ }^{5}$}

\author{
1 Projeto financiado pela Fundação de Amparo à Pesquisa do Estado de Minas Gerais - FAPEMIG. \\ 2 Programa de Pós-graduação em Zootecnia - UFLA, Lavras, MG. \\ 3 Departamento de Zootecnia/UFLA. \\ 4 Departamento de Zootecnia/UFV. \\ 5 UNIFENAS.
}

RESUMO - Objetivou-se neste experimento testar diferentes relações lisina digestível:proteína bruta (PB) em dietas para frangos de corte na fase inicial de criação. Utilizou-se um lote misto de 1.800 aves da linhagem Cobb, com um dia de idade. O delineamento foi inteiramente casualizado com um modelo de classificação hierárquica com três níveis de PB e quatro relações lisina digestível:PB. No ensaio de desempenho, as rações foram fornecidas a 30 aves em cada uma das cinco repetições. Aos 21 dias de idade, avaliaram-se consumo de ração, ganho de peso e conversão alimentar. Não houve efeito significativo das diferentes relações dentro dos três níveis de PB. Observou-se comportamento linear do ganho de peso nas relações de lisina dentro dos níveis de 18,5 e $21,5 \%$ de PB. A conversão alimentar melhorou linearmente segundo as relações de lisina dentro dos três níveis de PB estudados. O rendimento de carcaça elevou-se linearmente com o aumento das relações no nível de $15,5 \%$ de $\mathrm{PB}$, não sendo significativo nos demais níveis. No ensaio de metabolismo, as relações lisina digestível:proteína bruta apresentaram efeito linear sobre a EMAn (21,5\% de PB) e excreção de nitrogênio (18,5\% de PB) e efeito quadrático sobre a EMAn $(15,5$ e $18,5 \%$ de PB) e o coeficiente de retenção de $\mathrm{N}$ (15,5\% de PB). Considerando os resultados de ganho de peso, a relação ideal de lisina digestível:proteína bruta na fase inicial foi de $6,8 \%(18,5 \%$ de $\mathrm{PB})$ e $5,9 \%$ (21,5\% de PB) ou 1,26 e 1,27\% de lisina digestível. Os teores de PB das rações para frangos de corte na fase inicial podem ser reduzidos para $18,5 \%$, sem afetar o desempenho das aves, mas reduzindo a excreção de nitrogênio em $24 \%$, desde que as rações sejam suplementadas com aminoácidos sintéticos.

Palavras-chave: aminoácidos digestíveis, excreção, aves, nitrogênio, proteína ideal

\section{Digestible lysine:crude protein ratios on initial broiler diets - performance and metabolism}

\begin{abstract}
The experiment aimed to test different ratios digestible lysine:crude protein (CP) in diets for broiler until 21 days. One thousand and eight hundred 1-d birds of Cobb strain were allotted to a completely randomized design with a hierarchical rank model with three levels of CP and four ratios digestible lysine:CP was used. In the performance trial, the diets were fed to 30 birds in each of the five replicates. At 21 days of age, feed intake, weight gain and feed conversion were evaluated. A linear increase on weight gain was observed in the 18.5 and $21.5 \%$ of CP levels. Feed conversion improved linearly according to the ratios of lysine within the three levels of CP studied. Carcass yield increased linearly with increasing rations at the level of $15.5 \%$ of $\mathrm{CP}$, it not being significant at the other levels of $\mathrm{CP}$ studied. In the metabolism trial, the ratios digestible lysine:CP showed linear effect on EMAn (21.5\% of $\mathrm{CP})$ and nitrogen excretion (18.5\% of CP), quadratic effect on EMAn (15.5 and $18.5 \%$ of $\mathrm{CP})$ and $\mathrm{N}$ retention coefficient $(15.5 \%$ of $\mathrm{CP})$. Based on the results of weight gain, the ideal digestible lysine:CP ratio in the initial phase was of $6.8 \%(18.5 \%$ of $\mathrm{CP})$ and $5.9 \%$ ( $21.5 \%$ of $\mathrm{CP}$ ), or 1.26 and $1.27 \%$ of digestible lysine. The dietary CP contents fed to broilers in the initial phase can be reduced to $18.5 \%$, with no effect on bird performance, but by decreasing nitrogen excretion to $24 \%$, since the diets are supplemented with synthetic aminoacids.
\end{abstract}

Key Words: birds, digestible aminoacids, excretion, ideal protein, nitrogen

Este artigo foi recebido em 11/7/2006 e aprovado em 4/9/2007. 


\section{Introdução}

A suplementação com aminoácidos sintéticos, principalmente metionina e lisina, tem permitido considerável redução no nível de proteína bruta (PB) das dietas, foco da indústria avícola. Atualmente, é possível formular rações satisfazendo-se as necessidades específicas de aminoácidos essenciais, utilizando-se aminoácidos sintéticos, com base no conceito de proteína ideal, que tem a lisina como aminoácido padrão.

Segundo Van Cauwenberg \& Burnham (2001), a concentração de lisina digestível (LD) não deve estar acima de $6 \%$ da proteína da dieta para frangos de corte e de 5,5\% para poedeiras, destancando que relações superiores prejudicam o desempenho das aves. Gonzalez et al. (1997), por sua vez, recomendam uma relação de 5,5 a 6,0\% de lisina total na dieta, nas fases inicial e de crescimento, para máximo desempenho das aves.

Segundo Almeida et al. (2002), o aumento dos níveis de lisina acima do recomendado pelo NRC (1994) não influiu no desempenho e rendimento de carcaça dos frangos abatidos com 28, 35, 42 e 49 dias de idade.

Valério et al. (2003), estudando diferentes níveis de LD em rações em que se manteve ou não a relação aminoacídica para frangos de corte de 1 a 21 dias, mantidos em estresse por calor, com níveis de lisina de 0,92 a 1,16\% de LD, encontraram efeito quadrático para ganho de peso e consumo de ração, que aumentaram até os níveis de 1,14 e $1,09 \%$ de lisina, respectivamente. A conversão alimentar aumentou linearmente, mas foi ajustada ao modelo LRP, atingindo um platô no valor estimado de 1,097\% de lisina. Para a fase inicial, esses autores estimaram exigência de 1,14 e 1,22\% de LD em rações convencional e com relação aminoácidica, respectivamente.

Blair et al. (1999) mostraram claramente o papel dos aminoácidos otimizando a eficiência alimentar e a retenção de nitrogênio em frangos de corte, sob três níveis de aminoácidos (110,100 e 90\% das recomendações práticas) e dois níveis de proteína, confirmando que a excreção de nitrogênio é influenciada tanto pelo conteúdo de proteína da dieta como pelo conteúdo dietético de aminoácidos. Dentro de um mesmo nível protéico, o aumento do conteúdo de aminoácidos pela suplementação com lisina, treonina, metionina e triptofano melhorou a retenção de nitrogênio em frangos de corte e poedeiras. Esses autores afirmam, ainda, que a redução de $10 \%$ no nível de PB da dieta pode reduzir, em média, 18,5\% na excreção de nitrogênio, o que poderia acarretar redução de $20 \%$ na produção de amônia.

Van Cauwemberghe \& Burnhan (2001) afirmam que é possível reduzir o teor de PB dietética de 7 a 10\%, formula- das com base em aminoácidos digestíveis e suplementadas com lisina, metionina e treonina, sem prejuízo no desempenho das aves. Isto significa que a relação lisina:PB não pode ultrapassar $6 \%$ na fase inicial e 5,8\% na fase final, para não afetar o desempenho das aves. Esta diminuição de proteína acarreta redução de $15 \%$ na excreção de nitrogênio, mantendo-se o mesmo desempenho.

Assim, esta pesquisa foi conduzida para determinar os valores energéticos e a digestibilidade de nutrientes e a relação ideal entre LD e PB da ração, formuladas com base no conceito de proteína ideal, para frangos de corte, no período de 1 a 21 dias de idade.

\section{Material e Métodos}

O experimento foi conduzido no Setor de Avicultura do Departamento de Zootecnia da Universidade Federal de Lavras (UFLA), Lavras, Minas Gerais. Foram utilizados 1.800 pintos de corte, machos e fêmeas, da marca comercial Cobb, de 1 dia de idade, com peso médio inicial de 42,4 $\pm 3 \mathrm{~g}$. As aves foram alojadas e distribuídas aleatoriamente em boxes, com piso coberto com cama de maravalha. Cada boxe continha um comedouro tubular, um bebedouro pendular, 15 aves machos e 15 fêmeas.

Adotou-se delineamento inteiramente casualizado, seguindo um modelo com dois critérios de classificação hierárquica: três níveis de PB $(15,5 ; 18,5$ e 21,5\%) e quatro diferentes relações (quatro níveis de LD) dentro de cada nível de proteína, que corresponderam às seguintes porcentagens dos níveis de PB: 5,0; 6,0; 7,0 e 8,0\% em relação à ração com 15,5\% de PB; 5,0;5,6;6,2 e 6,8\% em relação à ração com 18,5\% de $\mathrm{PB}$ e 5,0; 5,3; 5,6 e 5,9\% em relação à ração com $21,5 \%$ de PB). Dessa forma, a composição nutricional correspondeu aos seguintes níveis de LD: 15,5\% de PB $-0,78 ; 0,93 ; 1,09$ e $1,24 \% ; 18,5 \%$ de PB $-0,93 ; 1,04$; 1,$15 ; 1,26 ;$ e $21,5 \%$ de PB - 1,08; 1,14; 1,20 e $1,27 \%$.

As rações foram fornecidas a 30 aves em cada uma das cinco repetições. Os níveis de PB foram fixados tendo-se como padrão as recomendações de Rostagno et al. (2000) e a relação LD:PB, partindo-se daquela indicada por Gonzáles et al. (1997) para lisina total:PB (6,0\%).

As rações, isoenergéticas $(3.000 \mathrm{kcal} / \mathrm{kg}$ ), foram constituídas basicamente de milho e farelo de soja, alimentos que forneceram a proteína natural. Os níveis nutricionais dos demais nutrientes seguiram as recomendações de Rostagno et al. (2000) e as rações formuladas com base na proteína ideal indicada por esses autores.

Para os cálculos dos teores de PB e de energia metabolizável (EM) das rações (Tabelas 1 e 2), não foram considerados os valores protéicos e energéticos dos 
aminoácidos. Ração e água foram fornecidas à vontade e a luz, durante 24 horas diárias, entre luz natural e artificial.

As variáveis de desempenho avaliadas foram o consumo de ração, o ganho de peso e a conversão alimentar, durante o período experimental.

Aos 21 dias de idade, foram abatidas duas aves por parcela, segundo a média do lote, totalizando 120 aves. As aves foram identificadas, pesadas e abatidas por desloca- mento cervical. Após a sangria, os animais foram pesados novamente. Posteriormente, foram retiradas as penas e vísceras e, então, pesadas novamente, para determinação do rendimento de carcaça.

Para determinação dos valores de EMAn e coeficientes de digestibilidade aparente da MS, consumo, excreção absoluta e coeficiente de retenção de nitrogênio; por frangos de corte, na fase inicial, recebendo dietas com diferentes

Tabela 1 - Composição química dos ingredientes utilizados nas rações experimentais ${ }^{1}$

\begin{tabular}{lcrc}
\hline Ingrediente & MS & PB & Ca \\
\hline Milho disponível & $0,03^{\#}$ \\
Farelo de soja & 87,98 & 8,49 & $0,24^{\#}$ \\
Fosfato bicálcico & 89,69 & 44,65 & $0,18^{*}$ \\
Calcário calcítico & & & 24,21 \\
\hline
\end{tabular}

${ }^{1}$ Análises realizadas no Laboratório de Pesquisa Animal DZO-UFLA.

\# Dados compilados de Rostagno et al. (2000).

Tabela 2 - Composição centesimal dos ingredientes das dietas experimentais da fase inicial

\begin{tabular}{|c|c|c|c|c|c|c|c|c|c|c|c|c|}
\hline \multirow{2}{*}{$\frac{\text { Proteína bruta }(\%)}{\text { Relação lisina digestível:PB }(\%)}$} & \multicolumn{4}{|c|}{15,5} & \multicolumn{4}{|c|}{18,5} & \multicolumn{4}{|c|}{21,5} \\
\hline & 5 & 6 & 7 & 8 & 5 & 5,6 & 6,2 & 6,8 & 5 & 5,3 & 5,6 & 5,9 \\
\hline Lisina digestível (\%) & 0,78 & 0,93 & 1,09 & 1,24 & 0,93 & 1,04 & 1,15 & 1,26 & 1,08 & 1,14 & 1,20 & 1,27 \\
\hline \multicolumn{13}{|l|}{ Ingrediente } \\
\hline Milho (\%) & 72,00 & 71,20 & 71,21 & 71,21 & 66,75 & 66,14 & 65,17 & 63,86 & 56,70 & 56,44 & 56,12 & 55,66 \\
\hline Farelo de soja (\%) & 20,50 & 20,65 & 20,35 & 20,63 & 28,06 & 28,18 & 28,36 & 28,61 & 36,54 & 36,60 & 36,65 & 36,74 \\
\hline Óleo $(\%)$ & 1,46 & 1,55 & 1,50 & 1,30 & 1,50 & 1,83 & 1,83 & 2,26 & 3,00 & 3,05 & 3,16 & 3,31 \\
\hline Fosfato bicálcico (\%) & 1,95 & 1,90 & 1,91 & 1,86 & 1,86 & 1,86 & 1,86 & 1,86 & 1,81 & 1,81 & 1,81 & 1,81 \\
\hline Calcário (\%) & 1,00 & 1,05 & 1,0 & 1,04 & 1,02 & 1,01 & 1,01 & 1,01 & 0,98 & 0,98 & 0,98 & 0,98 \\
\hline L-lisina $(\%)$ & 0,18 & 0,35 & 0,55 & 0,74 & 0,11 & 0,25 & 0,40 & 0,53 & 0,05 & 0,13 & 0,21 & 0,30 \\
\hline DL-metionina (\%) & 0,09 & 0,20 & 0,32 & 0,43 & 0,13 & 0,21 & 0,29 & 0,37 & 0,18 & 0,22 & 0,26 & 0,32 \\
\hline L-valina $(\%)$ & 0,00 & 0,08 & 0,20 & 0,32 & 0,00 & 0,04 & 0,12 & 0,21 & 0,00 & 0,00 & 0,03 & 0,09 \\
\hline L-arginina $(\%)$ & 0,00 & 0,10 & 0,25 & 0,42 & 0,00 & 0,00 & 0,08 & 0,21 & 0,00 & 0,00 & 0,00 & 0,00 \\
\hline L-treonina $(\%)$ & 0,00 & 0,03 & 0,14 & 0,23 & 0,00 & 0,00 & 0,06 & 0,13 & 0,00 & 0,00 & 0,00 & 0,00 \\
\hline L-isoleucina $(\%)$ & 0,00 & 0,03 & 0,07 & 0,23 & 0,00 & 0,00 & 0,04 & 0,11 & 0,00 & 0,00 & 0,00 & 0,00 \\
\hline L-triptofano $(\%)$ & 0,00 & 0,00 & 0,02 & 0,04 & 0,00 & 0,00 & 0,00 & 0,00 & 0,00 & 0,00 & 0,00 & 0,00 \\
\hline L-fenilalanina $(\%)$ & 0,00 & 0,00 & 0,09 & 0,27 & 0,00 & 0,00 & 0,00 & 0,06 & 0,00 & 0,00 & 0,00 & 0,00 \\
\hline Outros 1 & 2,78 & 2,86 & 2,04 & 0,97 & 0,77 & 0,80 & 0,77 & 0,77 & 0,77 & 0,77 & 0,77 & 0,77 \\
\hline \multicolumn{13}{|l|}{ Composição nutricional } \\
\hline Energia metabolizável (kcal/kg) & 3.000 & 3.000 & 3.000 & 3.000 & 3.000 & 3.000 & 3.000 & 3.000 & 3.000 & 3.000 & 3.000 & 3.000 \\
\hline $\mathrm{P}$ disponível (\%) & 0,45 & 0,45 & 0,45 & 0,45 & 0,45 & 0,45 & 0,45 & 0,45 & 0,45 & 0,45 & 0,45 & 0,45 \\
\hline $\mathrm{Ca}(\%)$ & 0,96 & 0,96 & 0,96 & 0,96 & 0,96 & 0,96 & 0,96 & 0,96 & 0,96 & 0,96 & 0,96 & 0,96 \\
\hline Metionina + cistina digestível $(\%)$ & 0,55 & 0,66 & 0,78 & 0,88 & 0,66 & 0,74 & 0,82 & 0,89 & 0,77 & 0,81 & 0,85 & 0,90 \\
\hline Treonina digestível (\%) & 0,52 & 0,55 & 0,64 & 0,73 & 0,62 & 0,62 & 0,68 & 0,74 & 0,73 & 0,73 & 0,73 & 0,75 \\
\hline Triptofano digestível (\%) & 0,16 & 0,16 & 0,17 & 0,20 & 0,20 & 0,20 & 0,20 & 0,20 & 0,24 & 0,24 & 0,24 & 0,25 \\
\hline Valina digestível (\%) & 0,64 & 0,72 & 0,84 & 0,96 & 0,76 & 0,81 & 0,89 & 0,97 & 0,89 & 0,89 & 0,92 & 0,98 \\
\hline Arginina digestível (\%) & 0,91 & 1,00 & 1,14 & 1,31 & 1,12 & 1,13 & 1,21 & 1,32 & 1,36 & 1,36 & 1,36 & 1,36 \\
\hline Isoleucina digestível (\%) & 0,58 & 0,61 & 0,71 & 0,81 & 0,71 & 0,71 & 0,75 & 0,82 & 0,93 & 0,84 & 0,85 & 0,85 \\
\hline Fenilalanina + tirosina digestível $(\%)$ & 1,16 & 1,16 & 1,25 & 1,43 & 1,39 & 1,39 & 1,39 & 1,45 & 1,62 & 1,62 & 1,62 & 1,62 \\
\hline Glicina + serina digestível $(\%)$ & 1,46 & 1,46 & 1,46 & 1,46 & 1,76 & 1,76 & 1,76 & 1,76 & 2,06 & 2,06 & 2,06 & 2,06 \\
\hline Histidina digestível (\%) & 0,40 & 0,40 & 0,40 & 0,40 & 0,46 & 0,46 & 0,46 & 0,46 & 0,53 & 0,53 & 0,53 & 0,53 \\
\hline Leucina digestível (\%) & 1,36 & 1,35 & 1,35 & 1,37 & 1,55 & 1,54 & 1,54 & 1,54 & 1,72 & 1,72 & 1,72 & 1,72 \\
\hline $\begin{array}{l}\text { Aminoácidos essenciais/ } \\
\text { aminoácidos não-essenciais }\end{array}$ & $52 / 48$ & $54 / 46$ & $57 / 43$ & $59 / 41$ & $52 / 48$ & $53 / 47$ & $54 / 46$ & $55 / 45$ & $52 / 48$ & $52 / 48$ & $52 / 48$ & $53 / 47$ \\
\hline
\end{tabular}

\begin{tabular}{llllllllllllll}
\hline Custo $(\mathrm{R} \$ / \mathrm{kg})$ & 0,45 & 1,09 & 2,39 & 4,56 & 0,47 & 0,58 & 1,21 & 2,36 & 0,49 & 0,50 & 0,59 & 0,78
\end{tabular}

\footnotetext{
1 Sal, premix mineral e vitamínico (Fornecimento por kg de ração: 70 mg Zn, 50 mg Fe, 8,5 mg Cu, 0,2 mg Co, 75 mg Mn e 1,5 mg I; 3,3 mg vit. B, 53 $\mathrm{mg}$ nicotinamida, 2,2mg vit. $B_{1}, 16 \mathrm{mcg}$ vit. $B_{12}, 6 \mathrm{mg}$ vit. $B_{2}, 1 \mathrm{mg}$ de ac. fólico, $13 \mathrm{mg}$ de ac. pantotênico, $2,5 \mathrm{mg}$ vit. $\mathrm{K}_{3}, 30 \mathrm{mg}$ vit. $\mathrm{E}, 1,2 \mathrm{mg}$ vit. $A$ $2,2 \mathrm{mg}$ vit $\mathrm{D}_{3}$, cloreto de colina $70 \%$ ), Caulim (inerte).
} 
relações de $\mathrm{LD}$ e PB, foi conduzido um ensaio de metabolismo utilizando o método tradicional de coleta total de excretas, em sala de metabolismo, no Setor de Avicultura do Departamento de Zootecnia da Universidade Federal de Lavras (UFLA). O ensaio foi conduzido no período de 14 a 21 dias.

Inicialmente, as aves foram criadas em boxes de alvenaria, com piso coberto com maravalha. Aos 14 dias de idade, cinco aves foram retiradas de cada unidade experimental, segundo o peso médio do lote, e transferidas para as gaiolas para ensaios de metabolismo, totalizando 300 aves. Foram utilizadas gaiolas $(50 \mathrm{~cm} \times 50 \mathrm{~cm}$ x e $50 \mathrm{~cm})$ de arame galvanizado, que continham um bebedouro tipo pressão, um comedouro individual tipo calha com borda, para evitar desperdícios, e uma bandeja revestida com plástico resistente, para coleta das excretas. A temperatura da sala foi controlada com ventiladores e exaustores automáticos e a iluminação foi constante durante todo o período experimental (24 horas de luz artificial).

As dietas experimentais foram as mesmas do ensaio de desempenho. A coleta de excretas foi realizada uma vez ao dia, na parte da manhã, durante todo o período de coleta (três dias), conforme metodologia de coleta total de excretas descrita por Rodrigues et al. (2005).

Durante o período de coleta, as excretas foram acondicionadas em sacos plásticos identificados e armazenados em freezer até o período final de coleta, quando foram descongeladas, pesadas, homogeneizadas, reservando-se até $500 \mathrm{~g}$ para futuras análises.

As amostras passaram por pré-secagem em estufa de ventilação forçada a $55^{\circ} \mathrm{C}$ até peso constante. Após a présecagem, as amostras foram processadas em moinho com peneira de porosidade de $2 \mathrm{~mm}$.

Determinaram-se os teores de MS, energia bruta (EB) e nitrogênio $(\mathrm{N})$ das excretas e das rações experimentais. As análises foram realizadas no Laboratório de Pesquisa Animal do DZO/UFLA. Para determinação da EM aparente corrigida pelo balanço de nitrogênio (EMAn), a EB das rações e das excretas foram determinadas em bomba calorimétrica modelo Parr-1261. Com base nos resultados laboratoriais obtidos, foram calculados os valores da EM aparente corrigida para o balanço de nitrogênio (EMAn) utilizando-se a equação descrita por Matterson et al. (1965):

EMAn da ração $(\mathrm{kcal} / \mathrm{kg})=($ EBingerida $-($ EBexcretada + $8,22 \times \mathrm{BN})) / \mathrm{MS}$ ingerida

em que: EMAn = energia metabolizável aparente corrigida pelo balanço de nitrogênio; EB excretada = energia bruta excretada EB ingerida $=$ EB ingerida $;$ MS ingerida $=$ MS ingerida $; \mathrm{BN}=$ balanço de nitrogênio $=(\mathrm{MS}$ ingerida $\mathrm{x} \mathrm{N}$ dieta) - (MS excretas $\mathrm{x} N$ excretas).

O método utilizado para determinação do nitrogênio das rações e excretas foi o de Kjeldahl, conforme métodos constantes em Silva (1990). Para o cálculo dos coeficientes de digestibilidade aparente da MS e de retenção de nitrogênio na MS, utilizou-se a seguinte fórmula:

$\mathrm{CD}=((\mathrm{g}$ de nutriente ingerido $-\mathrm{g}$ de nutriente excretado)/g de nutriente ingerido) $) * 100$

As análises estatísticas foram realizadas utilizando-se o pacote computacional SAEG (UFV, 1993). A análise de variância foi realizada considerando-se o método dos quadrados mínimos e o modelo com dois critérios de classificação hierárquica, conforme apresentado a seguir:

Ensaio na fase inicial:

$$
\mathrm{y}_{\mathrm{ijk}}=\mu+\mathrm{P}_{\mathrm{i}}+\mathrm{R}_{\mathrm{j}} / \mathrm{P}_{\mathrm{i}}+\mathrm{e}_{\mathrm{ijk}},
$$

em que $y_{\text {ijk }}=$ observação em cada repetição, com i $=1,2,3$; $\mathrm{j}=1,2,3,4$ e k = 1,2,3,4,5; $\mu$ = média geral; $\mathrm{P}_{\mathrm{i}}=$ efeito donível de $\mathrm{PB} i ; \mathrm{R}_{\mathrm{j}} / \mathrm{P}_{\mathrm{i}}=$ efeito da relação lisina digestível: $\mathrm{P}_{\mathrm{j}}$, dentro do nível de PB i; $e_{i j k}=$ erro associado a cada observação, que por pressuposição é NID $\left(0, \sigma^{2}\right)$.

Dentro de cada nível de PB estudado, foi realizada análise de regressão polinomial para determinar a melhor relação LD:PB, optando-se pelo modelo que melhor se ajustasse aos dados.

\section{Resultados e Discussão}

As relações de LD:PB não afetaram $(\mathrm{P}>0,05)$ o consumo de ração em nenhum dos três níveis de $\mathrm{PB}$ estudados (Tabela 3). O ganho de peso das aves aumentou linearmente $(\mathrm{P}<0,05)$ com o incremento das relações LD:PB nos níveis de 18,5 e $21,5 \%$ de PB (Figura 1).

Observou-se também diminuição no índice de CA $(\mathrm{P}<0,01)$, à medida que se elevaram as relações de LD:PB (Figura 2).

Estes resultados se assemelham aos de Surisdiarto et al. (1991), e o comportamento linear indica que a relação ótima de LD:PB não se encontra no intervalo estudado, porém discordam dos obtidos por Gonzáles et al. (1997), que recomendam manter nível de lisina de 6,0\% em relação à proteína dietética. Contradizem também os resultados obtidos por Van Cauwenbergue \& Burnham (2001), que indicaram a relação máxima de $6 \%$, visto que valores superiores poderiam prejudicar o desempenho das aves, fato não observado quando se utilizaram relações superiores a $6,0 \%$ neste trabalho. 
Tabela 3 - Efeito de diferentes relações lisina digestível:proteína bruta (PB) sobre consumo de ração $(\mathrm{CR})$, ganho de peso (GP) e conversão alimentar (CA) de frangos de corte na fase inicial ( 1 a 21 dias de idade)

\begin{tabular}{lccccc}
\hline $\begin{array}{l}\text { Nível } \\
\text { PB }(\%)\end{array}$ & $\begin{array}{c}\text { Relação lisina } \\
\text { digestível:PB }\end{array}$ & $\begin{array}{c}\text { Lisina digestível } \\
(\%)\end{array}$ & $\begin{array}{c}\text { CR } \\
(\mathrm{g})\end{array}$ & $\begin{array}{c}\mathrm{GP}^{1} \\
(\mathrm{~g})\end{array}$ & $\mathrm{CA}^{2}$ \\
\hline 15,5 & 5,0 & 0,78 & 1.082 & 575 & 1,88 \\
& 6,0 & 0,93 & 1.071 & 610 & 1,77 \\
& 7,0 & 1,09 & 1.112 & 654 & 1,70 \\
& 8,0 & 1,24 & 1.057 & 621 & 1,70 \\
\hline Média & & & 1.080 & 615 & 1,76 \\
\hline 18,5 & 5,0 & 0,93 & 1.088 & 657 & 1,66 \\
& 5,6 & 1,04 & 1.087 & 668 & 1,63 \\
& 6,2 & 1,15 & 1.098 & 693 & 1,59 \\
& 6,8 & 1,26 & 1.118 & 732 & 1,53 \\
\hline Média & & & 1.098 & 689 & 1,60 \\
\hline 21,5 & 5,0 & 1,08 & 1.075 & 639 & 1,68 \\
& 5,3 & 1,14 & 1.099 & 693 & 1,59 \\
& 5,6 & 1,20 & 1.117 & 753 & 1,49 \\
& 5,9 & 1,27 & 1.128 & 775 & 1,46 \\
\hline Média & & & 1.105 & 715 & 1,55 \\
\hline CV (\%) & & & 4,86 & 7,71 & 4,53 \\
\hline
\end{tabular}

1 Efeito linear para os níveis 18,5 e $21,5 \%$ de $P B(P<0,05$ e $P<0,01)$.

2 Efeito linear para os três níveis de $\mathrm{PB}(\mathrm{P}<0,01)$.

$18,5 \%$ de $\mathrm{PB}$

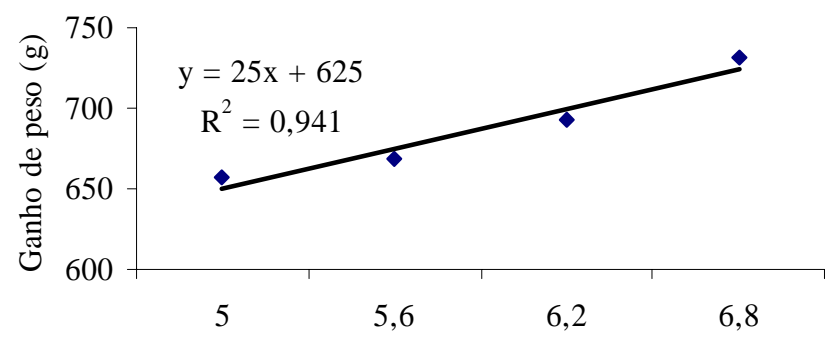

Relação lisina digestível:PB

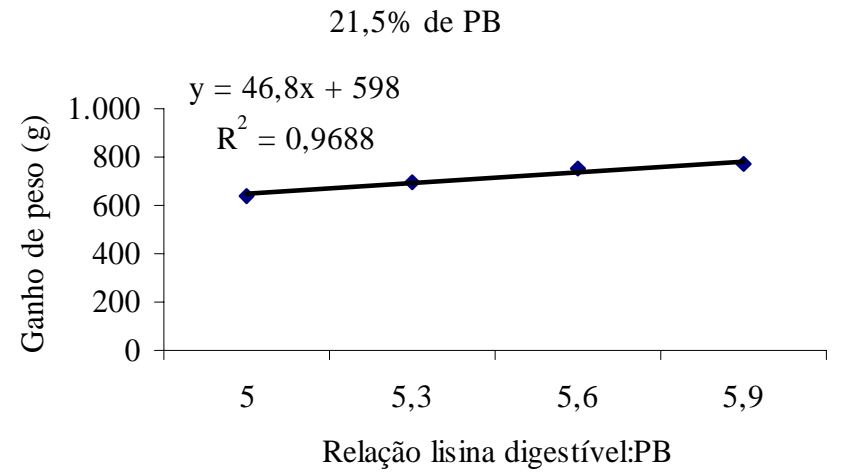

Figura 1 - Ganho de peso de frangos de corte recebendo rações com diferentes relações lisina digestível:PB aos 21 dias de idade.
Observou-se ainda que, independentemente da relação LD:PB utilizada, o desempenho das aves que receberam as rações com menor nível de $\mathrm{PB}(15,5 \%)$ foi inferior $(\mathrm{P}<0,01)$ aos demais níveis de PB utilizados, corroborando aqueles observados por Almeida et al. (2002) e Silva et al. (2006).

Estes resultados indicam a necessidade de se adotar nível mínimo de PB na forma intacta na ração, o que, neste estudo, seria de $18,5 \%$ de PB, dentro do conceito de proteína ideal.

Dentro de cada nível de PB, observou-se que as rações com baixa relação LD:PB apresentaram os piores resultados de desempenho, confirmando os obtidos por Sterling et al. (2003). Comparando-se estes resultados com aqueles

$15,5 \%$ de $\mathrm{PB}$

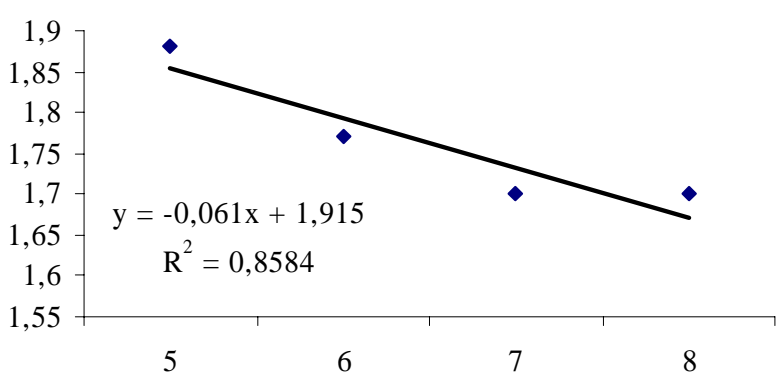

$18,5 \%$ de $\mathrm{PB}$

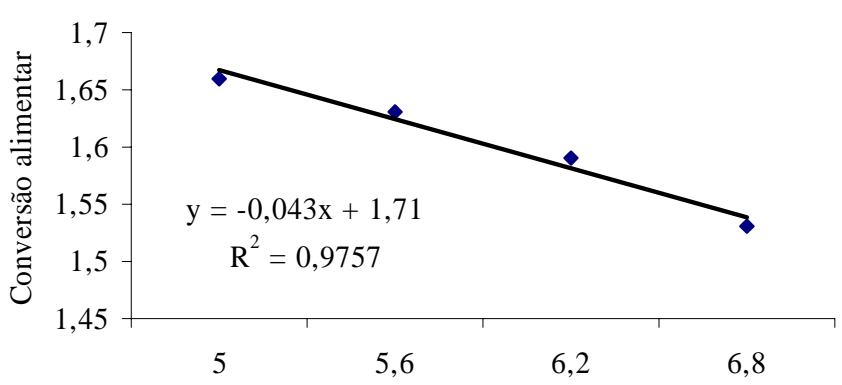

$21,5 \%$ de $\mathrm{PB}$

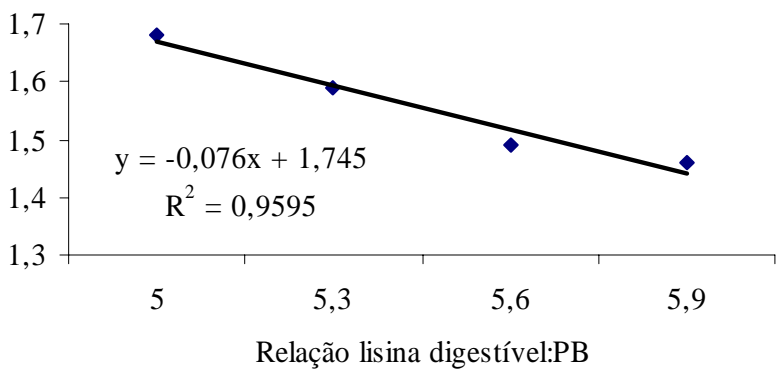

Figura 2 - Conversão alimentar de frangos de corte recebendo rações com diferentes relações lisina digestível:PB aos 21 dias de idade. 
encontrados por Valério et al. (2003), que trabalharam com nível de LD de 1,04 a 1,22\%, mantendo a relação aminoacídica, observa-se aumento linear do ganho de peso das aves, não havendo efeito sobre o consumo de ração e melhora na conversão alimentar de forma linear. Esses autores concluíram que seria recomendável utilizar teor de LD dentro do padrão de proteína ideal (e 1,22\%). Neste estudo, obteve-se exigência de lisina para a fase inicial acima de $1,24 \%$, demonstrando que as relações e o nível de lisina recomendados podem estar subestimados na literatura e, portanto, são necessários novos trabalhos para se avaliarem os níveis de LD e a relação ideal com a PB da dieta. O mesmo resultado foi obtido por Conhalato et al. (2000), que indicaram o nível de exigência de 1,20\% de LD para esta fase.

As tabelas brasileiras de exigências nutricionais de aves e suínos (Rostagno et al., 2005) trazem a recomendação de exigência de LD, dos 8 aos 21 dias, para machos e fêmeas de desempenho médio, de 1,146 e $1,126 \%$, respectivamente. Nota-se que estas exigências estão aquém dos resultados obtidos neste trabalho, pois, a partir da ponderação desses dados, obter-se-ia média de LD em um lote misto de $1,207 \%$. Os resultados indicam exigência superior a 1,26\% para toda a fase. Há que se considerar, entretanto, a relação custo/benefício do uso de elevados níveis de LD na ração, que levam à necessidade de utilização de inclusão de aminoácidos sintéticos para seu balanceamento.

As diferentes relações de LD:PB aos 21 dias de idade influenciaram positivamente $(\mathrm{P}<0,01)$ o rendimento de carcaça no nível de 15,5\% de PB (Tabela 4), não sendo significativo $(\mathrm{P}>0,05)$ nos demais níveis estudados.

Os resultados indicam que o aumento da relação LD:PB maximizou o rendimento de carcaça no nível de 15,5\% de PB, porém, o mesmo não ocorreu nos níveis de 18,5 e $21,5 \%$ de PB, resultado que corrobora os obtidos por Valério et al. (2003), que não encontraram efeito dos diferentes níveis de LD sobre o rendimento de carcaça.

As relações LD:PB apresentaram efeito significativo para EMAn (Figura 3), dentro dos três níveis de PB, com efeito quadrático nos níveis de 15,5 e $18,5 \%(\mathrm{P}=0,035 \mathrm{e}$ $\mathrm{P}=0,0029)$ e efeito linear $(\mathrm{P}=0,018)$ no nível de $21,5 \%$ de PB.

O coeficiente de digestibilidade da MS foi influenciado significativamente pelas diferentes relações LD:PB, com comportamento linear nos níveis de 15,5 e 21,5\% de PB $(\mathrm{P}=0,0378$ e $\mathrm{P}=0,01171)\left(\mathrm{Y}=70,395+0,6589 \mathrm{X}, \mathrm{R}^{2}=0,65\right.$ e $\left.\mathrm{Y}=56,62+144,03 \mathrm{X}, \mathrm{R}^{2}=0,84\right)$ e quadrático no nível de $18,5 \%$ de PB $(\mathrm{P}=0,00528)\left(\mathrm{Y}=-29,41+33,68 \mathrm{X}-2,7533 \mathrm{X}^{2}\right.$, $\left.\mathrm{R}^{2}=0,99\right)$, apresentando ponto de máxima $(6,12 \%)$ no nível de $18,5 \%$ de PB (Tabela 5).
Tabela 4 - Efeito de diferentes relações lisina digestível:proteína bruta (PB) sobre o rendimento de carcaça (RCA) de frangos de corte aos 21 dias de idade

\begin{tabular}{lccc}
\hline $\begin{array}{l}\text { Nível } \\
\text { PB (\%) }\end{array}$ & $\begin{array}{r}\text { Relação lisina } \\
\text { digestível:PB }\end{array}$ & Lisina digestível (\%) & RCA (\%) \\
\hline 15,5 & 5,0 & 0,78 & 56,45 \\
& 6,0 & 0,93 & 58,70 \\
& 7,0 & 1,09 & 59,97 \\
& 8,0 & 1,24 & 59,59 \\
\hline Média & & & 58,68 \\
\hline 18,5 & 5,0 & 0,93 & 58,69 \\
& 5,6 & 1,04 & 59,35 \\
& 6,2 & 1,15 & 60,24 \\
\hline Média & 6,8 & 1,26 & 60,79 \\
\hline 21,5 & 5,0 & & 59,77 \\
& 5,3 & 1,08 & 58,21 \\
& 5,6 & 1,14 & 59,09 \\
& 5,9 & 1,20 & 60,33 \\
\hline Media & & & 59,95 \\
\hline CV & & & 59,39 \\
\hline
\end{tabular}

${ }^{1}$ Efeito linear no nível $15,5 \%$ de $\mathrm{PB}(\mathrm{P}<0,01)$.
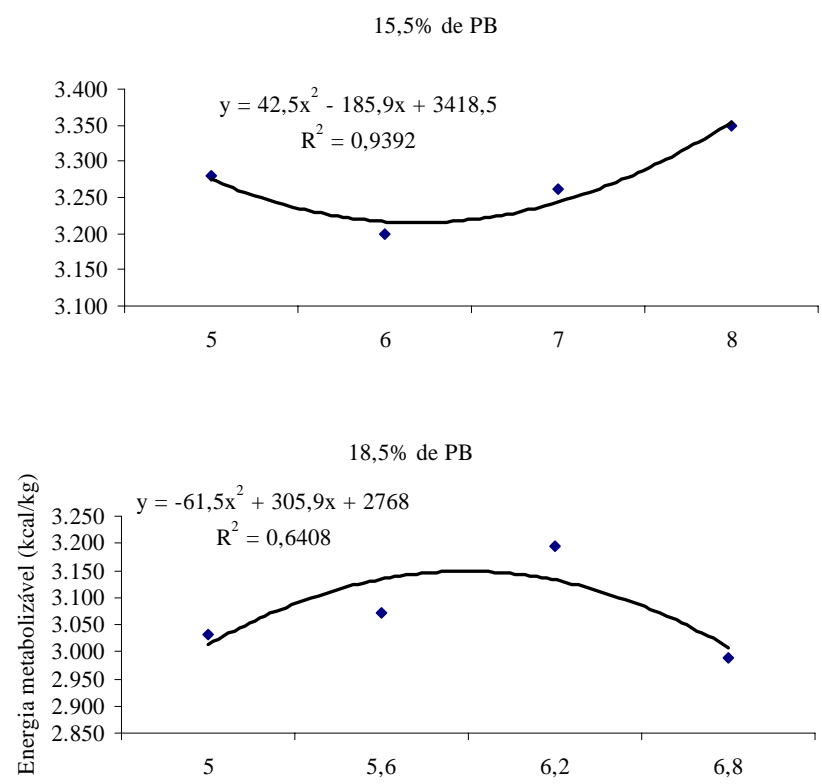

$21,5 \%$ de $\mathrm{PB}$

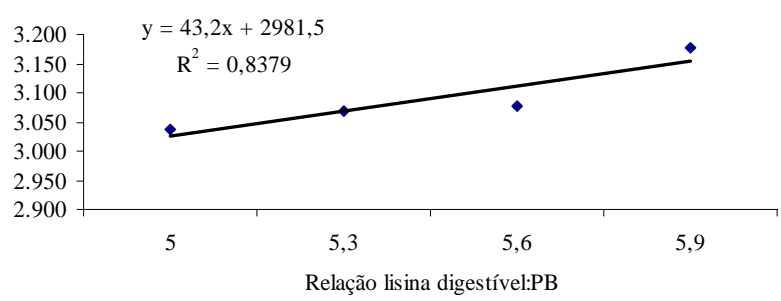

Figura 3 - Energia metabolizável aparente corrigida na MS de rações de frangos de corte com diferentes relações lisina digestível:PB dos 14 aos 21 dias de idade. 
Tabela 5 - Efeito de diferentes relações lisina digestível:proteína bruta (PB) sobre os valores de energia metabolizável aparente corrigida na MS (EMAN), coeficiente de digestibilidade da MS (CDMS), excreção (EXCN) e coeficiente de retenção de nitrogênio (CRN) de frangos de corte dos 14 aos 21 dias de idade

\begin{tabular}{|c|c|c|c|c|c|c|}
\hline Nível PB (\%) & Relação lisina digestível/PB & Lisina digestível & $\operatorname{EMAn}^{1}(\mathrm{kcal} / \mathrm{kg})$ & $\mathrm{CDMS}^{2}(\%)$ & $\mathrm{EXCN}^{3}(\mathrm{mg})$ & $\mathrm{CRN}^{4}(\%)$ \\
\hline \multirow{2}{*}{15,5} & 6,0 & 0,93 & 3.199 & 75,24 & 781 & 70,67 \\
\hline & 8,0 & 1,24 & 3.349 & 75,43 & 916 & 66,59 \\
\hline Média & & & 3.272 & 74,68 & 869 & 67,68 \\
\hline \multirow{2}{*}{18,5} & 6,2 & 1,15 & 3.194 & 73,42 & 1.192 & 60,62 \\
\hline & 6,8 & 1,26 & 2.987 & 72,36 & 1.332 & 65,73 \\
\hline Média & & & 3.077 & 72,23 & 1.185 & 64,23 \\
\hline \multirow[t]{2}{*}{21,5} & 5,0 & 1,08 & 3.036 & 70,05 & 1.481 & 60,59 \\
\hline & 5,3 & 1,14 & 3.068 & 70,44 & 1.567 & 59,49 \\
\hline $\mathrm{CV}$ & & & 2,65 & 1,92 & 8,89 & 3,99 \\
\hline
\end{tabular}

1 Efeito quadrático para os níveis 15,5 e $18,5 \%$ e linear no nível de $21,5 \%$ de PB.

2 Efeito linear para os níveis 15,5 e $21,5 \%$ e quadrático no $21,5 \%$ de PB.

3 Efeito linear no nível de $18,5 \%$ de PB.

4 Efeito quadrático no nível de $15,5 \%$ e cúbico nos níveis 18,5 e $21,5 \%$ de PB.

Não houve efeito significativo sobre a excreção de nitrogênio ( $\mathrm{P}>0,05)$ para os níveis de 15,5 e $21,5 \%$ de $\mathrm{PB}$, mas sim efeito linear $(\mathrm{P}<0,01)$ no nível de $18,5 \%$ de $\mathrm{PB}$ (Figura 4$)$.

$O$ coeficiente de retenção de nitrogênio apresentou comportamento quadrático no nível de $15,5 \%$ de PB $(\mathrm{P}<0,05)$, com ponto máximo de 6,53\% de $\mathrm{LD}$ em relação à PB da ração, e cúbico nos níveis de 18,5 e 21,5\% de PB $(\mathrm{P}<0,01)$. Observa-se que o coeficiente de retenção de nitrogênio acompanhou a variação de LD, com melhores resultados nos níveis em que se observou a relação mais próxima de AAE:AANE.

\section{$18,5 \% \mathrm{~PB}$}

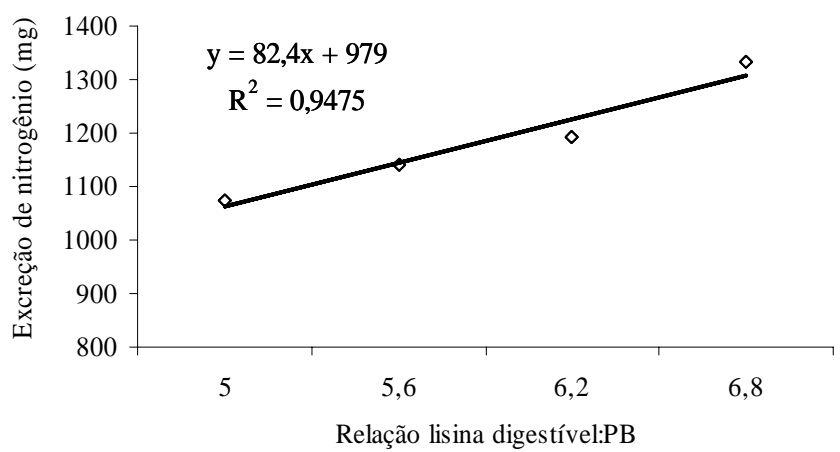

Figura 4 - Excreção de nitrogênio por frangos de corte recebendo rações com diferentes relações lisina digestível:PB dos 14 aos 21 dias de idade.
Nota-se que a redução no teor de PB da dieta até o nível de $18,5 \%$ de PB (Tabela 5) possibilitou diminuição no nitrogênio excretado cerca de $24 \%$, confirmando os resultados de Blair et al. (1999), que afirmaram que esta diminuição na excreção poderia levar à redução na formação de gás amônia no interior do galpão de, aproximadamente, $20 \%$. Semelhantes também aos resultados de Silva et al. (2006), que encontraram redução no consumo e na excreção e melhora no coeficiente de retenção de nitrogênio, quando se reduziu o nível de PB da ração para 17,0\% de PB com a suplementação de fitase.

A menor ingestão e a menor excreção acarretaram melhora na retenção de $\mathrm{N}$ no organismo do animal, o que representaria diminuição de $8 \%$ na excreção de $\mathrm{N}$ para cada ponto percentual reduzido no teor de PB, próximo aos $10 \%$ encontrados por Dapoza (2002).

\section{Conclusões}

As relações LD:PB recomendadas para a fase inicial, considerando o desempenho das aves, são de $6,8 \%$ para o nível de $18,5 \%$ de $\mathrm{PB}-1,26 \%$ de LD e de $5,9 \%$ para o nível de $21,5 \%$ de $\mathrm{PB}-1,27 \%$ de $\mathrm{LD}$.

Considerando-se a excreção de nitrogênio, a melhor relação foi de 5,0\% de LD:PB.

$\mathrm{O}$ teor de $\mathrm{PB}$ dietético na fase inicial pode ser reduzido de 21,5 para $18,5 \%$, desde que a dieta seja suplementada com aminoácidos sintéticos. 


\section{Literatura Citada}

ALMEIDA, I.C.L.; MENDES, A.A.; GARCIA, R.G. et al. Efeito do nível de lisina da dieta e do sexo sobre o desempenho e rendimento de carcaça de frangos de corte. Revista Brasileira de Ciência Avicola, v.4, n.1, p.11-18, 2002.

BLAIR, R.; JACOB, J.P.; IBRAHIM, S. et al. A quantitative assessment of reduced protein diets and supplements to improve nitrogen utilization. Journal Applied of Poultry Research, v.8, n.1, p.25-47, 1999.

DAPOZA, C. El papel de los aminoácidos comerciales en la producción avícola. Selecciones Avícolas, v.44, n.8, p.513-518, 2002.

CONHALATO, G.S.; DONZELlE, J.L.; AlBINO, L.F.T. et al. Avaliação de rações contendo diferentes níveis de lisina digestível mantendo a relação aminoacídica para pintos de corte na fase de 1 a 21 dias de idade. Revista Brasilera de Zootecnia, v.29, n.6, p.2066-2071, 2000.

GATES, R.S. Poultry diet manipulation to reduce output of pollutants to environment. In: SIMPÓSIO SOBRE RESÍDUOS DA PRODUÇÃO AVÍCOLA, 2000, Concórdia. Anais... Concórdia: Embrapa Suínos e Aves, 2000. p.62-74.

GONZÁLEZ, R.R.F.; CAMACHO, D.Y.; CUARÓN, J.A. Requerimiento de proteína cruda en función a lisina, en dietas formuladas a proteína ideal para pollos de engorda. In: REUNIÓN NACIONAL DE INVESTIGACIÓN PECUARIA, 33., 1997, Veracruz. Memórias... Veracruz: 1997. (CD-ROM).

HEGER, J.; MENGESHA, S.;VODEHNAL, D. Effect of essencial total nitrogen ratio on protein utilization in growing pigs. British Journal of Nutrition, v.80, n.6, p. 537-544, 1998.

MACK, S.; BERCOVICI, D.; DE GROOTE, G. et al. Ideal amino acid profile and dietary lysine specification for broiler chickens of 20 to 40 days of ahe. British Poultry Science, v.40, n.2, p.257-265, 1999.

RODRIGUES, P.B.; MARTINEZ, R.S.; FREITAS, R.T.F. Influência do tempo de coleta e metodologia sobre a digestibilidade e o valor energético de rações para aves. Revista Brasileira de Zootecnia, v.34, n.30, p.882-889, 2005.

MATTERSON, L.D.; POTTER, L.M.; STUTZ, M.W. et al. The metabolizable energy of feed ingredients for chickens. Storss: The University of Connecticut, Agricultural Experiment Station, 1965. 11p. (Research Report, 7).

NATIONAL RESEARCH COUNCIL - NRC. Nutrient requirements of poultry. 9.ed. Washington, D.C.: National Academy Press, 1994. 155p.
PENZ JR., A.M. O conceito de proteína ideal para monogástricos. In: CONGRESSO INTERNACIONAL, 1.; CONGRESSO NACIONAL, 6.; CONGRESSO ESTADUAL DE ZOOTECNIA, 14., 1996, Porto Alegre. Anais... Porto Alegre: 1996. p.71-75.

ROSTAGNO, H.S.; ALBINO, L.F.T.; DONZELE, J.L. et al. Tabelas brasileiras para aves e suínos (composição de alimentos e exigências nutricionais). Viçosa, MG: Universidade Federal de Viçosa, 2000. 124p.

ROSTAGNO, H.S.; ALBINO, L.F.T.; DONZELE, J.L. et al. Tabelas brasileiras para aves e suínos (composição de alimentos e exigências nutricionais). Viçosa, MG: Universidade Federal de Viçosa, 2005. 186p.

SCOTT, T.A.; PAUL, J.W.; NEWBERRY, R.C. et al. Benefícios de las dietas con amino acidos balanceados. Avicultura Profesional, v.15, n.2, p.31-34, 1997.

SILVA, D.J. Análise de alimentos (métodos químicos e biológicos). Viçosa, MG: Universidade Federal de Viçosa, 1990. $160 \mathrm{p}$.

SILVA, Y.L.; RODRIGUES, P.B.; FREITAS, R.T.F. et al. Redução de proteína e fósforo em rações com fitase para frangos de corte no período de 1 a 21 dias de idade. Desempenho e teores de minerais na cama. Revista Brasileira de Zootecnia, v.3, p.840-848, 2006.

STERLING, K.G.; PESTI, G.M.; BAKALLI, R.L. Performance of broiler chicks fed various levels of dietary lysine and crude protein. Poultry Science, v.82, n.12, p.1939-1947, 2003.

SURISDIARTO, I.; FARRELL, D.J. The relationship between dietary crude protein and dietary lysine requirement by broiler chicks on diets with and without the "ideal amino acid balance". Poutry Science, v.70, n.4, p.830-836, 1991.

UNIVERSIDADE FEDERAL DE VIÇOSA - UFV. SAEG - Sistema de análises estatísticas e genéticas. Viçosa, MG: Central de Procesamento de Dados, 1993. 59p.

VALÉRIO, S.R.; OLIVEIRA, R.F.M.; DONZELE, J.L. et al. Níveis de lisina digestível em rações, em que se manteve ou não a relação aminoacídica, para frangos de corte de 1 a 21 dias de idade, mantidos em estresse por calor. Revista Brasileira de Zootecnia, v.32, n.2, p.361-371, 2003.

Van CAUWENBERGHE, S.; BURNHAM, D. New developments in amino acid and protein nutrition of poultry, as related to optimal performance and reduced nitrogen excretion. In: EUROPEAN SYMPOSIUM OF POULTRY NUTRITION, 13. 2001, Blankenberge. Proceedings... Blankenberge: 2001. (CR-ROM). 